\title{
Aproximación al suelo habitable en la Ribeira Sacra durante los siglos XIV y XV
}

\section{Approximation to the inhabitable ground in the Sacred Ribeira during XIV and XV centuries}

\author{
José Antonio López Sabatel
}

Diploma de Estudios Avanzados. Universidades de Santiago y Barcelona

\section{RESUMEN ABSTRACT}

Este estudio pretende establecer un acercamiento a la parte del espacio agrario destinada por el individuo para habitar en él, siempre en el seno del área de influencia de cinco cenobios situados a ambas márgenes del río Sil, en el tramo precedente a su desembocadura en el Miño.

No será objeto de este trabajo, por consiguiente, centrarse en el hábitat derivado de la ordenación del poder sobre el espacio ocupado. Por el contrario, este estudio se orientará hacia la observación del hábitat generado por la explotación del espacio ocupado, es decir el casal, como explotación campesina familiar y sus anexos y dependencias.

\section{PALABRAS CLAVE}

Ribeira Sacra, Sociedad feudal, Baja Edad Media, Historia Rural, Paisaje agrario, Hábitat, Casal, Anexos.
This study tries to establish an approach to the part of the agrarian space destined by the individual to always live in him in the area of influence of five monasteries located to both margins of the Sil river in the preceding section to its opening in the Miño. It will not be object of this work, therefore, to be centered in the habitat derived from the arrangement of the power on the occupied space. On the contrary, this study will orient towards the observation of the habitat generated by the operation of the occupied space that is to say, the country place, like operation familiar farmer and her annexed and dependencies.

\section{KEY WORDS}

Sacred Ribeira, feudal Society, Low Average Age, Rural History, agrarian Landscape, Habitat, Country place, House and annexed. 


\section{SIGLAS Y ABREVIATURAS}

CDE - DURO PEÑA, Emilio: El monasterio de San Esteban de Ribas de Sil, Orense, Instituto de Estudios Orensanos «Padre Feijoo», 1977.

CDPR - DURO PEÑA, Emilio: El monasterio de San Pedro de Rocas y su colección documental, Orense, Instituto de Estudios Orensanos «Padre Feijoo», 1972.

CDF - FERNÁNDEZ DE VIANA Y VIEITES, José Ignacio: Colección diplomática del monasterio de Santa María de Ferreira de Pantón, Lugo, Diputación provincial de Lugo, 1994.

CDC - FERNÁNDEZ SUÁREZ, Elisa: «El monasterio de Santa Cristina de Ribas de Sil», en Boletín Auriense, 4, (1974), pp. 7-66.

CDP - LUCAS ÁLVAREZ, Manuel y LUCAS DOMÍNGUEZ, Pedro: El priorato benedictino de San Vicenzo de Pombeiro y su colección diplomática en la Edad Media, A Coruña, Ediciós do Castro, 1996.

CDX - PEREIRA FERREIRO, Sara: «EI monasterio de Santa María de Xunqueira de Espadañedo y su colección diplomática» en Boletín Auriense, 9, (1979), pp. 151-230.

\section{LA DISPERSIÓN O CONCENTRACIÓN DE LA POBLACIÓN. EL CASAL COMO UNIDAD DE POBLAMIENTO Y EXPLOTACIÓN.}

El título de este apartado corresponde a los dos modelos de poblamiento rural que los historiadores manejan de forma alternativa en el estudio del hábitat medieval.

La tesis generalizada por geógrafos e historiadores acepta que se puede hablar de poblamiento disperso cuando los lugares de habitación se distribuyen a lo largo de espacios amplios compuestos por áreas de cultivo y pastos, impidiendo la proximidad entre los mismos. Por el contrario, el hábitat concentrado se caracterizará por una agrupación de casas en torno a la cual se extenderán de forma homogénea las tierras cultas ${ }^{1}$. En el primer supuesto estaríamos en presencia de explotaciones agrarias intercalares, o en nuestro caso casales, y en el segundo ante la aldea.

Sin embargo, esta distinción teórica está lejos de reproducirse de manera tan diáfana en la documentación de la época, como posteriormente se observará.

En la actualidad la distribución de la población en esta área de estudio seguirá los dos tipos de modelos generalizados en el interior agrícola gallego: el polinuclear con caserío claro y el nuclear en nebulosa. El primero de ellos se distingue al presentar el caserío o casal una formación compacta que dispone de alternancias de edificaciones y claros. Tanto es así que los espacios que deja pueden llegar a anular y ser mayores que las verdaderas separaciones físicas; en la toponimia se conocerán como lugares. El segundo tipo, la aldea nuclear en nebulosa, corresponde a formaciones de caserío claro de mucha menor entidad que las citadas anteriormente, pero conservando cada una de ellas su independencia e identidad.

${ }^{1}$ ÁLVAREZ BORGE, I.: La plena Edad media. Siglos XII-XIII, Madrid, Síntesis, 2003, p. 40. 
Serán mayoritarias en el mapa de cualquier parroquia, pero inferiores en habitantes. Al preguntar a los habitantes de dónde son responderán que del sitio de montes, etc. Así, pues, en la actualidad se podrá decir que en esta área rural el hábitat aparece fundamentalmente disperso en multitud de pequeños establecimientos ${ }^{2}$. En concreto en lo referente a la Tierra de Lemos esta dispersión se encuentra en el grado de «pequeños agrupamientos», de seis a diez casas y de cincuenta habitantes como máximo ${ }^{3}$.

El intento de establecer, ya desde la Alta Edad Media, la preeminencia de un modelo de hábitat sobre el otro dio lugar a enconados debates en el seno de la historiografía francesa ${ }^{4}$, lo que demuestra la dificultad de establecer una estructura homogénea de poblamiento para una región determinada.

En el caso de la Ribera Sacra, para este periodo la información extraída de las fuentes permite compartir las conclusiones de Álvarez Borge encaminadas a negar un universo uniforme de aldeas en la Baja Edad Media. Aún en este periodo, y como consecuencia del proceso de evolución del poblamiento a lo largo de los siglos anteriores, la convivencia dentro de un mismo ámbito territorial de los dos modelos de hábitat, el disperso y el concentrado, parece un hecho incuestionable. Es más, muchas estructuras estudiadas ni siquiera corresponderán de forma clara a alguno de estos modelos, lo que obliga a dirimir los grados de concentración o dispersión de un hábitat determinado 5 .

\footnotetext{
2 FARIÑA TOJO, J.: Los asentamientos rurales en Galicia, Madrid, Instituto de Estudios de Administración Local, 1980, pp. 115-116, 55-56 y 43.

${ }^{3}$ LLANO CABADO, P.: Arquitectura popular en Galicia, Santiago de Compostela, Colexio Oficial de Arquitectos de Galicia, 1989, vol I, p. 25.

${ }^{4}$ Las diferentes tesis estarán condenadas al continuo enfrentamiento. Aquí sólo pretendo establecer una pequeña muestra. Así, por ejemplo, Bois dará gran importancia a la concentración de hábitat en torno a la comunidad de aldea como protagonista principal del crecimiento agrícola antes del año mil (BOIS, G: La revolución del año mil, Barcelona, Crítica, 2000, pp. 143 y 144). Tesis que compartirá Genicot afirmando que Occidente pasará de la dispersión a la concentración de la población a partir de los siglos IX o X (GENICOT, L.: Comunidades rurales en el Occidente medieval, Barcelona, Crítica, 1993, p. 47). Bonnassie, por su parte, defenderá la teoría opuesta que establece la diseminación del hábitat como indicador de la expansión agraria alto-medieval en muchas regiones del sur de Francia (BONNASIE, P.: Del esclavismo al feudalismo en Europa occidental, Barcelona, Crítica, 1993, p. 126). Este mismo autor señala que Europa se cubriría de aldeas entre los siglos XI y XIII, fijándose el mapa aldeano a finales de este último siglo (BONNASIE, P.: Vocabulario básico de la historia medieval, Barcelona, Crítica, 1999, pp. 15 y 16). Para Duby la dispersión poblacional sería el modelo de habitat dominante a lo largo de los siglos XI, XII y XIII, siendo en el transcurso de esta última centuria cuando triunfase el reagrupamiento de la población (DUBY, G.: Economía rural y vida campesina en el Occidente medieval, Barcelona, Altaya, 1999, pp. 113-119 y 211-212). Toubert, en relación con Italia, apuntará el paso de un hábitat disperso y abierto a otro concentrado, este último manifestado a través del incastillamento a lo largo del siglo X (TOUBERT, P.: Castillos, señores y campesinos en la Italia medieval, Barcelona, Crítica, 1990, p. 204). Y, por último, Fossier situará no antes del siglo $X$ el nacimiento de las aldeas en el marco del «enceldamiento» (FOSSIER, R.: La infancia de Europa. Aspectos económicos y sociales, vol I, Barcelona, Labor, 1984, p. 83).

${ }^{5}$ ÁLVAREZ BORGE, I.: La plena..., pp. 40-41.
} 
En teoría, el casal es el punto de referencia incuestionable a la hora de hablar sobre el hábitat disperso intercalar ${ }^{6}$. El casal constituye el equivalente gallego al mas catalán y al solar castellano. Nos encontramos, por tanto, con un conjunto de propiedades que componen una explotación familiar, bien concentradas en torno a la vivienda y sus dependencias, bien en otras partes del terrazgo que completan la unidad básica ${ }^{7}$.

El casal, como el $\operatorname{mas}^{8}$, se fundamenta como la unidad básica de renta señorial. Su composición estará determinada por una casa de habitación y sus dependencias, también llamadas casas, así como por una huerta, una o varias cortiñas, tierras de labradío y terrenos incultos ${ }^{9}$. Esta estructuración irá encaminada a satisfacer la explotación mixta agrícola y ganadera constituyente de la base económica de dichos casales ${ }^{10}$.

Sin embargo, profundizando en el análisis de la documentación de este estudio, se abrirán dudas respecto al carácter genuinamente aislado del casal respecto a otros núcleos poblacionales.

Bouhier afirma que la aldea en Galicia se formará a partir del aglutinamiento de los diferentes casales ${ }^{11}$, durante los siglos XII, XIII y XIV. Esta apreciación parece confirmarse dada la gran presencia de la villa y la aldea en las diferentes colecciones diplomáticas. Sin embargo, María Luz Ríos Rodríguez aboga por una evolución muy particular del hábitat; a diferencia de Bouhier, la sitúa desde la concentración altomedieval a la dispersión en los siglos finales de la Edad Media. Según esta autora, la mayoría de las menciones de casales en los siglos XI y XII aparecen vinculadas a una villa, mientras que a raíz del XIII, y debido principalmente a la expansión del cultivo a zonas anteriormente desocupadas, el casal se erige como una unidad que, aunque próxima, se constituye en independiente de la aldea $^{12}$.

Si bien es mucho más frecuente encontrar en las fuentes de este periodo este segundo tipo de casal, corroborando así la proposición de la historiadora gallega, también se registran referencias a esta unidad de explotación y vivienda

\footnotetext{
${ }^{6}$ PORTELA SILVA, E.: La Región del obispado de Tuy en los siglos XII a XV. Una sociedad en la expansión y en la crisis, Santiago de Compostela, El Eco Franciscano, 1976, p. 86.

${ }^{7}$ LUCAS ÁLVAREZ, M. y LUCAS DOMÍNGUEZ, P.: El monasterio de San Clodio do Ribeiro en la Edad Media: estudio y documentos, A Coruña, Ediciós do Castro, 1996, p. 80.

${ }^{8}$ BOLÒS, J.: El mas, el pagès i el senyor, Barcelona, Curial, 1995, pp. 42 y 43.

${ }^{9}$ BOUHIER, A.: Ensaio xeográfico de análise e interpretación dun vello complexo agrario, vol II, s.I., Xunta de Galicia, 2001, p. 1212.

${ }^{10}$ RíOS RODRÍGUEZ, M.L.: «El casal medieval gallego: contribución al estudio de una entidad de poblamiento y explotación (siglos XI a XIII)» en Galicia en la Edad Media, Madrid, (1990), pp. 109-128/ 116118.

${ }^{11}$ BOUHIER, A: Ensaio xeográfico..., vol. Il, p. 1212.

12 RÍOS RODRÍGUEZ, M.L:. «El casal medieval gallego..., p. 111.
} 
en el ámbito de villas y aldeas. ${ }^{13}$ Circunstancia esta que hará del casal, según Portela Silva, no un núcleo de poblamiento sino meramente una unidad de explotación ${ }^{14}$. No obstante, el marcado interés de los rectores del señorío por mantener unos moradores estables en el seno de estas unidades ${ }^{15}$ coincide con la percepción del casal como núcleo de poblamiento continuado en el marco de la evolución de la presión demográfica de la segunda mitad del siglo XIII y de principios del $\mathrm{XIV}^{16}$.

En consecuencia, se hace necesario volver a la idea expuesta a lo largo de este apartado de negar una directa confrontación de dos modelos de hábitat claramente diferenciados, y aceptar el argumento que defiende un poblamiento totalmente heterogéneo impregnado de distintos niveles de concentración y dispersión de la población.

Esta circunstancia no será una prerrogativa de la época medieval. Incluso hoy día los geógrafos discrepan a la hora de incluir a los numerosísimos y pequeños núcleos de población característicos de la España atlántica dentro de alguno de estos dos modelos de hábitat ${ }^{17}$.

Así, parece tomar fuerza la tesis que defiende un tejido de asentamientos rurales que en Galicia se caracterizó, por lo menos hasta mediados del siglo XVIII, por ser una combinación de establecimientos dispersos y de establecimientos erigidos alrededor de un núcleo poblacional ${ }^{18}$.

\section{LA CASA Y LAS «CASAS». LOS ANEXOS DE LA VIVIENDA CAMPESINA.}

En lo que respecta a la vivienda campesina y a sus dependencias, la preocupación monástica, reflejada en las disposiciones contractuales, se centrará en exigir su buen estado de conservación y, si fuese menester, incluso su construcción ${ }^{19}$, así como, en ocasiones, la de imponer los materiales de estas edificaciones, seguramente con el fin de asegurarse una cierta solidez de las mismas.

${ }^{13}$ CDPR. Doc 73: ...dous nosos casales que nos avemos en Esgos, na vila de Soutelo, na friiguesía de Santa Vaya..., p. 184.

Docs 88, 96, 107, CDPR., pp. 196, 201-202, y 209.

Docs 170 y 256, CDE., pp. 385 y 413-414.

Doc 17, CDX, p. 177.

${ }^{14}$ PORTELA SILVA, E.: La Región del..., p. 85.

${ }^{15}$ CDP Doc 60: ... o noso casal que dizen de Outeyro...per tal pleito e su tal condiçón que vos que o moredes e pobredes e façades morar o pobrar per vos ou per outro..., p. 118.

${ }^{16}$ PORTELA SILVA, E.: La Región del..., p. 86.

${ }^{17}$ SAAVEDRA, P.: «O hábitat no noroeste peninsular nos ss. XVI-XIX» en Torres Luna, María del Pilar de, et alii, Espacios rurais e sociedades campesinas, Santiago de Compostela, Universidad de Santiago de Compostela, (1997), pp. 173-193/ 174.

${ }^{18}$ O'FLANAGAN, P.: Xeografía histórica de Galicia, Vigo, Xerais, 1996, p. 90.

${ }^{19}$ CDP. Doc 239: ... et corregades as casas et as tenades bem paradas...., p. 307.

CDP. Doc 153: ...Outrosy vos aforamos herdade en que façades duas casas...., p. 229. 
De esta forma, la teja ${ }^{20}$, la paja o el colmo y la madera ${ }^{21}$ estarán presentes en los techos.

La cubierta de la casa ocuparía, sin lugar a dudas, un lugar de primer orden en las preocupaciones del campesino a la hora de edificar su casa. Circunstancia esta que no es de extrañar si tenemos en cuenta la dificultad que entraña su construcción, unida al hecho de ser la primera en sufrir las inclemencias meteorológicas ${ }^{22}$. Esta preocupación también la tendrán los rectores monásticos a la hora de establecer las condiciones del aforamiento de las viviendas como se refleja en la documentación ${ }^{23}$.

El campesinado utilizaría para la elaboración de sus cubiertas aquellos materiales más asequibles, según la exigencia del clima y del terreno ${ }^{24}$.

Uno de los más difundidos en la baja Edad Media, en la actualidad marginado a escasas y localizadas áreas, será el colmo o paja de centeno. Su fácil adquisición, su liviandad y su capacidad para cubrir bien y guardar con eficacia el calor interior de las viviendas ${ }^{25}$ serán razones que expliquen su éxito.

La techumbre de teja, en cambio, es el sistema de más éxito en Galicia en la actualidad. Este tipo de cobertura, introducido por los romanos, garantiza un cubrimiento inmejorable dadas las condiciones climatológicas de Galicia, ya que gracias a su peso y a su forma cóncava hará frente de manera inmejorable a los efectos tanto de la lluvia como del viento ${ }^{26}$.

Por último, la madera servirá para la construcción de armazones sobre los se extenderán las referidas cubiertas de teja o paja.

La madera y la piedra serán los elementos constructivos de cualquier tipo de edificación más difundidos en esta área ${ }^{27}$. Las propiedades de la madera para resguardar al campesino contra el frío y la resistencia de la piedra al fuego y al

${ }^{20}$ CDP. Doc 133: ... con huna casa tellada que hy esta, que he deste herdamento...., p. 206.

CDF. Doc 207: ...e cubriredes a meetade da cassa da parte da nosa orta de tella...., p. 263.

Doc 211, CDPR., p. 246. En este documento los foristas dan tres moyos de teja al receptor del foro para que cubra con ellos una de las casas aforadas.

${ }^{21}$ CDF. Doc 180: ...e teñades as cassas feitas e cubiertas de madera e de palla...., p. 224.

Doc 78, CDPR., p. 188. Una de las condiciones principales del foro será la de la edificación por parte del forero de unas casas en el seno de un casal en los dous annos primeiros que veen, e as cubrades de madeira e de colmo.

${ }^{22}$ LLANO CABADO, P.: Arquitectura popular en..., vol I, p. 65.

${ }^{23}$ CDP. Doc 102: ...e con tal condiçon que moredes o dito lugar e tenades as ditas casas cuuertas e ben paradas..., p. 174.

${ }^{24}$ OTERO PEDRAYO, R.: Historia de Galiza, vol II, Buenos Aires, Ediciones Nos, 1962, p. 40.

${ }^{25}$ LORENZO FERNÁNDEZ, X.: A casa, Vigo, Galaxia, 1982, p. 41.

${ }^{26}$ LLANO CABADO, P.: Arquitectura popular en..., vol I, p. 70.

${ }^{27}$ Doc 218, CDPR., p. 248. Una de las condiciones de este foro a cumplir por parte del receptor del mismo será la de corregir una casa de pedra e de madeyra e de tella e que seja asobrada. 
agua ${ }^{28}$, así como la disponibilidad de ambos materiales, explicarán el uso generalizado de los mismos.

En cuanto a la estructura y distribución interna de las viviendas campesinas nada aporta la documentación. Sin embargo, es lógico pensar que en un periodo en el que el habitante de estas tierras, además de labriego, había de ser constructor, las casas campesinas debían de ser objeto de unos métodos de edificación bastante simples ${ }^{29}$. No hay que olvidar que estas viviendas estarán estrechamente unidas desde que se erigen no solamente a los materiales de fácil acceso del terreno circundante, sino también a las condiciones técnicas y económicas de la agricultura. De este modo, todo en ellas estará orientado hacia el trabajo agrícola o ganadero, no dejando nada a lo trivial, sacrificándose así incluso el bienestar de sus moradores. ${ }^{30}$

Así, pues, aunque es posible que las viviendas campesinas alcanzasen los dos pisos $^{31}$, los problemas de equilibrio que implicaba en la estructura la apertura de ventanas y la falta de cristal para cubrir las mismas, unido al intenso viento gélido del invierno, que se colaba por todos los resquicios, hacía de la casa labriega un lugar oscuro, iluminado trémulamente por el fuego del hogar, velas o candiles ${ }^{32}$, dotado solamente de pequeños orificios con el objetivo de favorecer una mínima ventilación ${ }^{33}$. La escasa ventilación distaba de ser una opción; ante el temor a helarse por los rigores del frío a lo largo de buena parte del año, los campesinos no tendrían más remedio que "asfixiarse» por el humo de los hogares y los hedores desprendidos, con la consabida falta de higiene de esta época ${ }^{34}$.

Ya ha quedado dicho en el apartado anterior que un casal se componía de diversas casas. Circunstancia esta que quedará claramente reflejada en la documentación ${ }^{35}$. No solamente en Galicia, sino también en el resto del reino de CastiIla, «casas» constituye un plural que hará referencia a las distintas dependencias de una sola de ellas ${ }^{36}$.

Así, pues, mientras que en el documento 97 de la colección diplomática de Ferreira un tal Juan Leitón morará en diferentes casas sin especificar la naturaleza de

\footnotetext{
${ }^{28}$ FOSSIER, R.: Historia del campesinado en el Occidente Medieval, Barcelona, Crítica, 1985, pp. 72-73.

${ }^{29}$ SÁNCHEZ CARRERA, M.C.: El Bajo Miño en el siglo XV. El espacio y los hombres, A Coruña, Fundación Pedro Barrié de la Maza, 1997, p. 94.

${ }^{30}$ ARIĖS, P, et alii: Historia de la vida privada, vol II, Madrid, Taurus, 2001, p. 461.

${ }^{31}$ LLANO CABADO, P.: Arquitectura popular en..., vol I, p. 49.

${ }_{32}$ POUNDS, N.J.G.: La vida cotidiana: Historia de la cultura material, Barcelona, Crítica, 1992, p. 253.

${ }^{33}$ SÁNCHEZ CARRERA, M.C.: El Bajo Miño en el siglo XV..., p. 94.

${ }^{34}$ POUNDS, N.J.G.: La vida cotidiana...., p. 251.

${ }^{35}$ CDF. Doc 65: ... per tal plleito que o llavredes ben e o paredes ben e façades as quasas e as moredes per vos ou per outre que seya voso semellável... ., p. 83.

CDF. Doc 76: ... per tal pleyto et contyçón que lavredes et paredes bem e mantenades o casar en boo estado e ergades y dúas casas..., p. 96.

${ }^{36}$ CARLÉ, M.C.: «La casa en la Edad Media castellana» en Cuadernos de Historia de España, Buenos Aires, Instituto de Historia de España, 67-68, (1982), pp. 165-229/ 187.
} 
las mismas ${ }^{37}$, en el documento 165 incluido en la misma colección la abadesa de dicho cenobio afora tres casas, una cocina situada entre la corte y el horno para «cocer» el pan ${ }^{38}$.

Así, pues, la cocina y la corte, y en ocasiones también el horno, serán las construcciones auxiliares más estrechamente ligadas a la casa de morada, o lugar de una sola pieza destinado a dormitorio ${ }^{39}$.

Será a partir de los siglos XII y XIII cuando se empiecen a consolidar los parámetros básicos que configurarán la casa campesina durante la Baja Edad Media. El modelo que seguirá la Europa atlántica (y obviamente también el territorio gallego) será el de una consecución de edificios independientes, dispuestos en el seno de una planta cuadrada o rectangular ${ }^{40}$.

Aparte de la proximidad de estas dependencias entre sít ${ }^{41}$, la información registrada en los documentos relativa a estas construcciones será nula.

Sin embargo, no será aventurado afirmar la importancia que para el campesino de este periodo tenían estas edificaciones.

Así, la cocina cumplimentaría ciertas funciones básicas, no sólo respecto a la preparación de las comidas y a la conservación de ciertos alimentos, sino también como espacio de sociabilidad de primer orden dentro del grupo doméstico y de este con el exterior ${ }^{42}$.

Mayor presencia documental tendrá la corte, aunque en la mayoría de los casos solamente sea en referencia a su construcción como condición estipulada en el contrato de aforamiento ${ }^{43}$. La relevancia de esta dependencia se manifiesta en el hecho de que en ocasiones la edificación de la corte, junto con la de la casa, será un requisito a cumplir por parte del forero si se quiere hacer con el dominio útil del conjunto de los bienes aforados ${ }^{44}$.

Tal importancia viene dada por una doble funcionalidad. La estabulación del ganado vacuno, mular ${ }^{45}$ y porcino ${ }^{46}$ y la adquisición de una fuente de abono o es-

${ }^{37}$ CDF. Doc 97: ... meu leiro de viña que está ante as portas das casas onde mora Juan Leitón..., p. 119.

${ }^{38}$ CDF. Doc 165: ...vos aforamos como dito he estas casas en que vos ora morades, a coçina e a outra casa que está par dela en que vos cosedes, e a casa da corte, que está da outra parte da cosiña, todas tres..., p. 204.

${ }^{39}$ SÁNCHEZ CARRERA, M.C.: El Bajo Miño en el siglo XV..., p. 95.

${ }^{40}$ CANTERA MONTENEGRO, E.: La agricultura en la Edad Media, Madrid, Arco Libros, 1997, p. 48.

${ }^{41}$ CDP. Doc 167: ... vos aforamos huna casa de corte que esta tras la vosa casa de coziña...., p. 242.

42 OTERO PEDRAYO, R.: Historia de..., vol II, p. 101.

${ }^{43}$ CDP. Doc 260: ... que labredes a dita herdade de Pena Faquina e faredes ende huna corte...., p. 326.

${ }^{44}$ CDF. Doc 109: ...et que façades y hua casa e hua corte..., p. 130.

45 SÁNCHEZ CARRERA, M.C.: El Bajo Miño en el siglo XV..., p. 99.

${ }^{46}$ CDPR. Doc 211: ... que façades hua corte para vosos porquos e gaando..., p. 246. 
trume de fácil disposición, al mezclarse en el piso de estos espacios las matas recogidas en el monte para hacer la cama del ganado con los excrementos de los mismos $^{47}$.

Los anexos a la vivienda campesina relacionados con el vino serán los lagares y las bodegas. El lagar era el lugar donde se iniciaba el proceso de vinificación de la uva. Como sucederá con las bodegas, estos anexos formarán parte del dominio útil del campesino al ser bienes sujetos a contratos de foro ${ }^{48}$. No obstante, es más frecuente la presencia de los lagares en la documentación en relación con la percepción de la renta a bica do lagar por parte de los representantes de las diferentes instituciones monásticas.

Más luz nos aportan los documentos en relación con las bodegas en cuyo seno se fermenta y se almacena el vino. Los monasterios se encargarán de exigir su construcción al forero ${ }^{49}$, circunstancia esta esclarecedora de la importancia que adquirirá la producción vitivinícola en este periodo. En cuanto a la ubicación de las bodegas, hay que decir que poco ha cambiado hasta nuestros días. Era usual que se estableciesen en las proximidades de las viviendas por razones obvias, no solamente de comodidad sino también de seguridad. Esta es la razón por la que en ocasiones, en los foros, la construcción de la casa y de la bodega en un mismo terreno son indisociables ${ }^{50}$.

También como en algunas áreas actuales de la Ribera Sacra, las bodegas se unían unas a otras formando un conjunto homogéneo dentro del ámbito aldeano ${ }^{51}$. Por último, también era posible localizar estas edificaciones a pie de viña, para facilitar el traslado de las uvas ${ }^{52}$. Con seguridad, estas bodegas contaban en su interior o en sus proximidades con un lagar donde se exprimiese la uva recién vendimiada, unificando espacialmente el proceso de la elaboración del vino.

Tampoco los materiales de construcción han diferido. La piedra y la madera imperarán en su estructura ${ }^{53}$, mientras la teja cubrirá su techumbre ${ }^{54}$. Con la intención de que las bodegas estén frescas se construirán en aquellos rincones que mejores condiciones presenten, siempre orientadas al norte y provistas de un piso de tierra;

${ }^{47}$ LLANO CABADO, P.: Arquitectura popular en..., vol I, p. 63.

${ }^{48}$ CDF. Doc 148: ... Et outrosí vos aforamos mays a casa do lagar que he do dito conbento..., p. 181.

${ }^{49}$ CDF. Doc 191: ...Et mays vos aforamos hun soar de adega que jas en braço con adega de Juan Rodrigues... a tal pleito e condiçón que poñades a dita biña en estes primeiros tres annos que bee e façades a dita adega en estes primeiros dous annos seguentes..., p. 239.

${ }^{50}$ Docs. 269 y 283 , CDPR., pp. 260 y $263-264$.

${ }^{51}$ CDE. Doc 143: ...vos aforamos hua nossa casa de adega que bos agora teedes a par da nosa iglesia de Santiago de Cangas, a qual dita casa está entre outra que agora hy ten Pedro Alfayate do Pontón e outra de Fernán Goterrez...., p. 375.

${ }^{52}$ CDP. Doc 249: ... vos aforamos as vinas que jasen en Riba de Sil... con sua adega..., p. 316.

${ }^{53} \mathrm{CDE}$. Doc 120: ...vos aforamos a nosa adega vella... a tal pleito et condiçón que a façades de pedra et de madeyra et a cubrades et paredes ben..., p. 351.

${ }^{54}$ CDE. Doc 143: ... vos aforamos hua nossa casa de adega... a tal pleito e condiçón... que cubrades a dita casa de tella por vosa custa..., p. 375. 
en sus muros de piedra se dispondrán pequeños tragaluces con el fin de ventilar la estancia y limitar el acceso al sol ${ }^{55}$.

En cuanto a los anexos relacionados con el cereal, la documentación hará referencia a los celeiros, y en mucha mayor medida a la airas o eiras.

El celeiro será el granero o silo donde se almacenará el grano, y constituirá un elemento más del núcleo del hábitat en las proximidades de la casa ${ }^{56}$.

Sin embargo, en las colecciones diplomáticas solamente aparecerá esta instalación como propiedad del monasterio para aludir al destino final que les espera a las rentas de las tierras de cereal ${ }^{57}$.

La eira también irá estrechamente ligada a la percepción de rentas. Era en estos lugares donde se procedía a mallar el cereal para separar el grano de la paja. En consecuencia, como se ha apuntado con anterioridad, este anexo se convertía en la primera parada del porcentaje de la producción asignado como renta en su camino hacia los celeiros monásticos ${ }^{58}$. En la documentación del monasterio de San Pedro de Rocas se utilizará el término vista dayra para designar el visto bueno otorgado por el monasterio cuando el forero quisiese mallar su grano. ${ }^{59}$

Estas instalaciones serán de tierra o de piedra, siendo las más comunes las primeras. En el primer caso hablamos de un pedazo de terreno bien nivelado y despejado de piedras; en el segundo supuesto nos encontramos con un cuadrángulo con una base formada por losas de piedra y rodeado con resaltes de este mismo material ${ }^{60}$.

Las eiras, además de privadas pueden ser comunales ${ }^{61}$. La documentación refleja que al menos estos espacios debían de ser compartidos, como se deja entrever en el foro no de una eira entera sino de su mitad ${ }^{62}$.

Por último, es preceptivo hacer mención de aquellos anexos relacionados con las castañas como son los canizos, «sequeiros» o secaderos y cisternas.

El canizo podía estar instalado en el interior de las viviendas, encima del hogar, o, si la producción de castañas era considerable, se erigían como construcciones

${ }^{55}$ LLANO CABADO, P.: Arquitectura popular en..., vol II, p. 379.

${ }^{56}$ MARIÑO VEIRAS, D.: Señorío de Santa María de Meira (De 1150 a 1525). Espacio rural, régimen de propiedad y régimen de explotación en la Galicia medieval, La Coruña, Ediciones Nos, 1983, p. 292.

${ }^{57}$ CDPR. Doc 64: ... Et tragernos edes o pan que nos aqueeçer dese casar o nosso celeiro de Lobazes ou Aurense..., p. 177.

CDF. Doc 65: ... e avedes de adozer o noso quinón da graa per vosa custa ó noso çelleyro do mosteiro..., p. 83.

${ }^{58} \mathrm{CDE}$. Doc 85: ... et que nos dedes ende cada anno terça de temporao et quarta de seródeo ena ayra do dito lugar (el casal aforado) por nosso moordomo...., p. 318.

${ }^{59}$ CDPR. Doc 257: ... vista dayra quando quiserdes mallar voso pan..., p. 257.

60 OTERO PEDRAYO, R.: Historia de..., vol II, p. 127.

${ }^{61}$ LORENZO FERNÁNDEZ, X.: A casa..., p. 148.

62 Doc 137, CDPR., p. 229. 
en las proximidades de las casas de morada. Consistía en unas tablas sobre las que se colocaban las castañas, que se iban secando a medida que pasaba el humo del fuego encendido en un primer piso bajo tierra ${ }^{63}$. Es habitual en los contratos de aforamiento relacionados con este producto que el pago de la renta por el mismo se efectúe en estas instalaciones ${ }^{64}$.

El sequeiro será una construcción de forma circular destinada a madurar y secar la producción de castañas en el seno de los propios sotos ${ }^{65}$. La documentación nada aporta para discernir si el objeto de este proceso eran las castañas con erizo o extraídas ya del mismo; en cambio, lo que sí evidencia es el interés del monasterio de Pombeiro en que se construyan y se mantengan en buen estado estos secaderos, dada la importancia de la castaña en su área de influencia ${ }^{66}$.

Una vez secas, las castañas se almacenaban en las cisternas que eran unos depósitos de piedra o de madera destinados a tal efecto ${ }^{67}$, hasta que se efectuase el reparto con el representante del monasterio enviado para la recaudación de la renta ${ }^{68}$.

${ }^{63}$ RíOS RODRíGUEZ, M.L.: «Soutos bravos y soutos mansos: el castaño en Galicia (siglos XII-XIV)», en El medio natural en la España medieval: Actas del I congreso sobre ecohistoria e historia medieval, Cáceres, Universidad de Extremadura, (2001), pp. 475-488/ 483-484.

${ }^{64}$ CDP. Doc 55: ... e que nos diades del de en cada hun ano a terça parte das castanas que Deus y der a deçeda do caniço...., p. 109.

${ }^{65}$ RíOS RODRÍGUEZ, M.L.: «Soutos bravos y..., p. 483.

CDE. Doc 140: ...convén a saber, que vos aforamos o nosso souto da Oveença con seu sequeyro..., p. 371.

${ }^{66}$ CDP. Doc 116: ... e que façades hy hun sequeyro para secar e coller as castannas..., p. 189.

CDP. Doc 150: ... e con tal condiçon que façades hy hun sequeyro e que o tenades cuberto e ben reparado..., p. 226.

${ }^{67}$ PICALLO FUENTES, H.: Castañas e castiñeiros como recursos económicos na Galiza do medievo» en Raígame: Revista de arte, cultura e tradicións populares, Ourense, Diputación de Ourense, 18, (2003), pp. 57-74/ 68.

${ }^{68}$ RÍOS RODRÍGUEZ, M.L.: «Soutos bravos y..., p. 484. 